\title{
POLIA - FEMININO DE POLIFILO
}

\section{Angela Harumi Tamaru}

\section{RESUMO}

Estudo sobre imagens-enigmas da obra Hypnerotomachia Poliphili, de 1499, editada por Aldus Manutius, e o movimento alegórico de arquitetura, amor e erotismo.

\section{PALAVRAS-CHAVE}

Arte da memória; Arquitetura; Tipografia

\section{POLIA - FEMALE OF POLIFILO}

\section{ABSTRACT}

Study on images-puzzles of the work Hypnerotomachia Poliphili, from 1499, edited by Aldus Manutius, and the allegorical movement of architecture, love and eroticism.

\section{KEYWORDS}

Art of memory; Architecture; Printing 


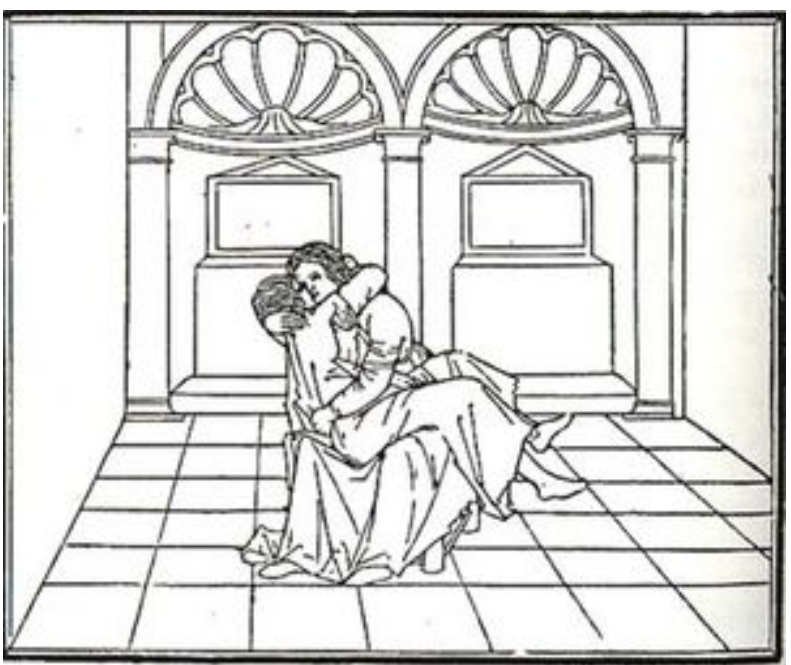

Ilustração da 'Hypnerotomachia Poliphili, ilustrador desconhecido

O Hypnerotomachia Poliphili, quase sempre abandonado na leitura ou na investigação, é um volume de enigmas que demonstram ser uma obra de ambição. Se ler e ver a obra seria um mero estoicismo contemplativo, é necessário, então, descobrir para reconstruir, ou seja, decifrar, dar sentido à obra. E são tantas as perguntas que se faz à obra atribuída a Aleph Francesco, escrita em 1499 e cuja ousada editoração fora realizada por Aldus Manutius, que é um desafio saber ler as imagens que se fazem "um conjunto hermético junto ou com letras de um alfabeto ou hieróglifos egípcios”?

Para se ler e decifrar as imagens dessa obra magnífica, ou seja, buscar seus significados, ainda há muito a ser feito pela humanidade. Os meus apontamentos neste artigo serão nesse sentido, da leitura da obra alegórica presentes nessa obra que tantas traduções mereceram, mas que parecem razoáveis serem pensadas enquanto "A batalha de amor em sonho de Polifilo”.

Antes de chegar ao seu destino, Polifilo faz uma viagem da alma ao labirinto, representado pelas figurações: cela, selva, livro e sonho. Andar por esses percursos é tão difícil quanto decifrar a leitura das manchas do jaguar constelado ou dos astros no firmamento de Jorge Luís Borges.

Sendo assim, vou seguir uma proposição dada por Rodrigo Almeida Bastos em um notável texto que aproxima "Arquitetura, amor e erotismo”, que considero bastante pertinente a essa interpretação: o reconhecimento do amor, por parte do renascimento, como sentimento ideal relacionado à noção do belo, anunciado na relação do homem com a vida e com as coisas nela envolvidas, mediadas e engendradas pela arte e pela arquitetura.

Este conceito é apontado, contemporaneamente, por parte de alguns teóricos da arquitetura, como experiência erótica, que levaria ao pansexualismo, cujos hieróglifos tem o papel de explicar o sentido metafórico da realização de polifilo com o corpo arquitetônico e erótico-amoroso com que se depara em sonho, sendo este representado nas formas fálicas e arredondadas, indicando masculino e feminino, como sugerem estes exemplos figurativos: 

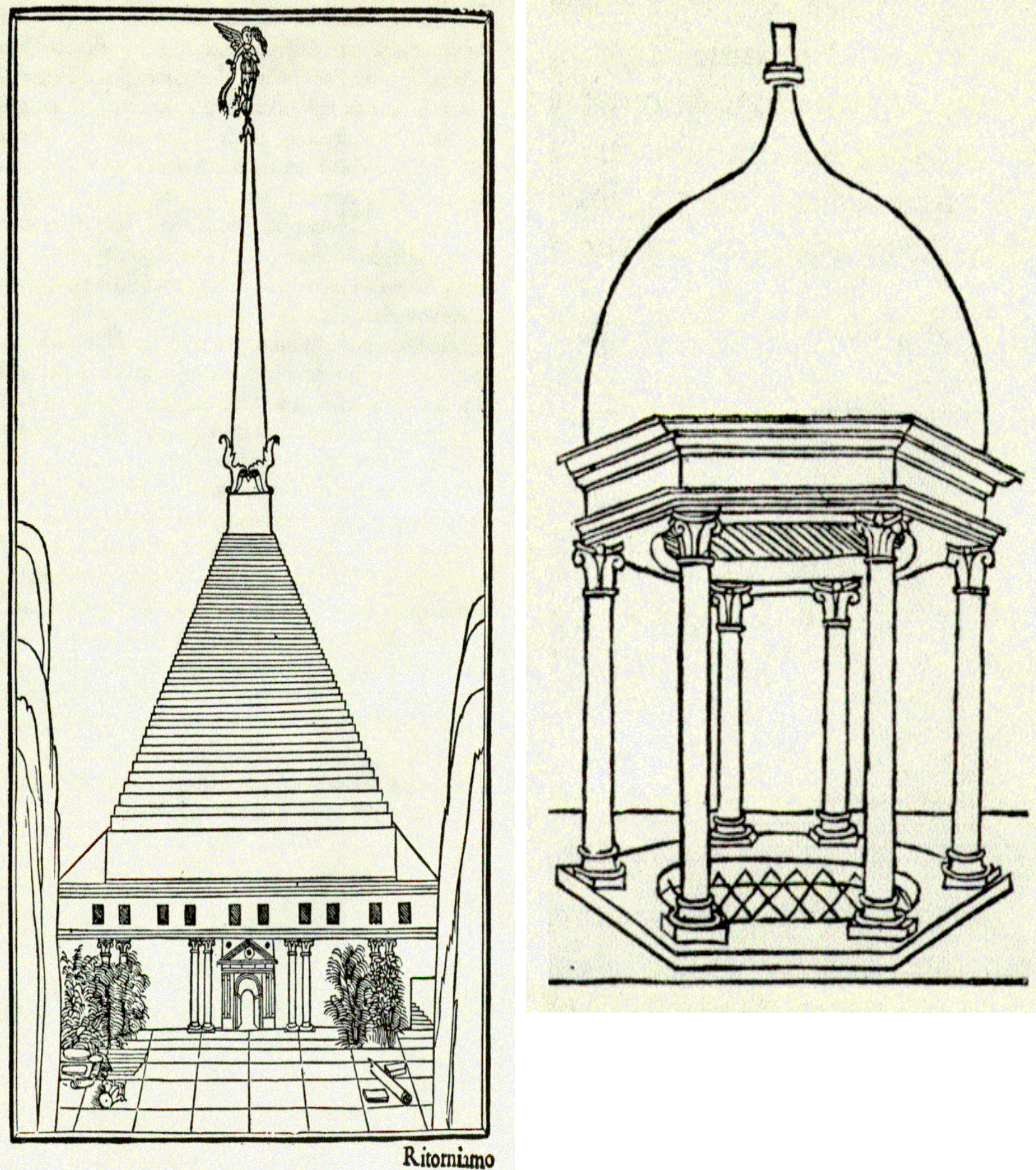

Para comprovação dessa interpretação, valeria a pena fazer uma incursão sobre os possíveis significados presentes nos nomes das personagens. Poliphilo é uma junção de dois radicais gregos polis + philo. O primeiro poderia ser interpretado tanto como "muitos" - Poliphilo sacia-se com muitas e variadas ninfas - quanto como "cidade"; sendo este último o de maior sentido para esta análise; philía significa amor. Deste modo, a personagem protagonista teria buscado em sonho atingir a necrópole, cidade dos mortos, a fim de se encontrar com sua amante Polia, seu objeto de desejo. 


\title{
Área Temática: Educação Visual, Linguagens Visuais e Arte
}

Passeando, para tanto, por toda a cidade, numa profusão de imagens arquitetônicas, cujas formas fálicas alegorizariam o reencontro do homem com a sua própria “poiesis”, ou seja, sua obra-de-arte. E quem seria Polia? Não seria, pois, Polia, à moda de Pigmalião, que esculpiu sua Galatéia tal como desejava encontrar-se com a obra, uma variação feminina do mesmo radical polis?

Na seqüência, a bela imagem que nos proporciona um artista, Jean Léon Gérôme: Pigmalião e Galatéia, 1890, um dos mitos que contam a origem das artes.

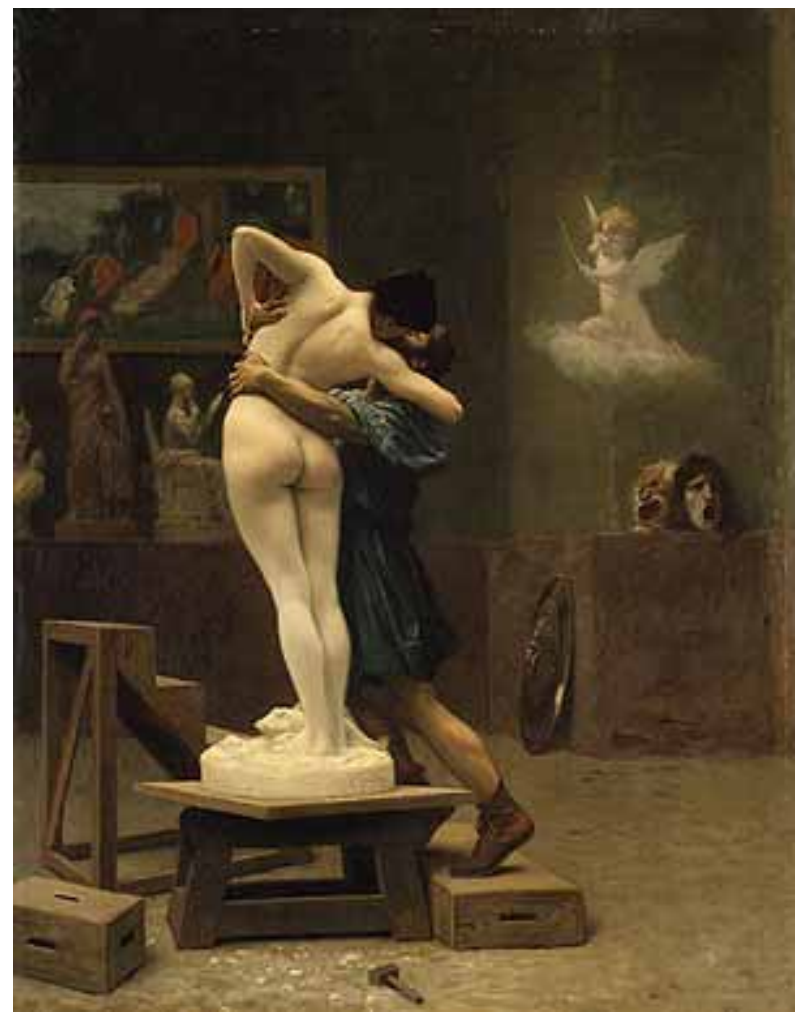

Pigmalião e Galatéia, 1890

Assim diz Bastos:

\begin{abstract}
Não será difícil imaginar o escultor em seu trabalho criativo. Ele acurou e preparou os instrumentos; examinou o alvíssimo marfim; fizera, certamente, alguns esboços, ideando os contornos, as linhas e as curvas, o decoro das expressões e dos movimentos; concebera o rosto. Seu trabalho se conduz como em um ritual no qual a preparação, que solicita e envolve o artista, enuncia o encontro com a obra.
\end{abstract}

Fazendo tais aproximações, poderíamos, então, pensar que Polia nada mais seria que obra mesmo de Polifilo. Talvez isso justifique o fato de a ela ser destinado apenas 30 páginas na vasta obra, desmentindo a idéia de se tratar de uma estória de amor e reforçando seu conceito de obra didática, apropriada à demonstração de valores clássicos, apresentando os outros $90 \%$ da obra acontecimentos ligados à arte, predominantemente, arquitetônica.

Bernardo Tsumi (1975), citado por Bastos, indica duas naturezas paradoxais para a arquitetura: a pirâmide, que ele interpreta como coisa mental, relativa ao conceito, que representaria a tradição, a 
teoria e a história; e o labirinto, coisa sensível, experimentada no espaço através dos sentidos, que representaria a cópula, a relação inegável entre corpo e arquitetura.

Pérez-Gómez, também citado por Bastos, construindo uma epifania erótica da arquitetura, afirma que a hypnerotocmachia satisfaz seu objetivo porque demonstra que o sentido da arquitetura não reside simplesmente numa satisfação intelectual, numa questão formal de relações proporcionais ou estéticos, mas se origina em um impulso erótico espontâneo, a partir da necessidade em satisfazer uma sede física.

Ou seja, se Polifilo tivesse bebido da água da fonte, saciando-se logo no início da narrativa, não teria se reconciliado com a produção cultural da humanidade enquanto condição existencial. Não lhe seria necessário uma Polia, uma Vênus material para sua satisfação erótica.

Decifrada essa parte, o acróstico identificado por Aldo Manuzio, formado pelas letras iniciais capitulares da obra, "Frade Francisco Colonna amou muitíssimo Polia”, continua com sentido, ainda que não seja da realização amorosa entre amantes como se pensa num primeiro momento.

Polifilo, sendo o que sonha estar perdido a princípio, põe-se de novo a sonhar, projetando-se, desta vez, na ninfa mais bela - Polia -, um seu duplo feminino, com o fim de sentir espiritualmente a volúpia, transformando-a em obra-de-arte, uma realidade artística.
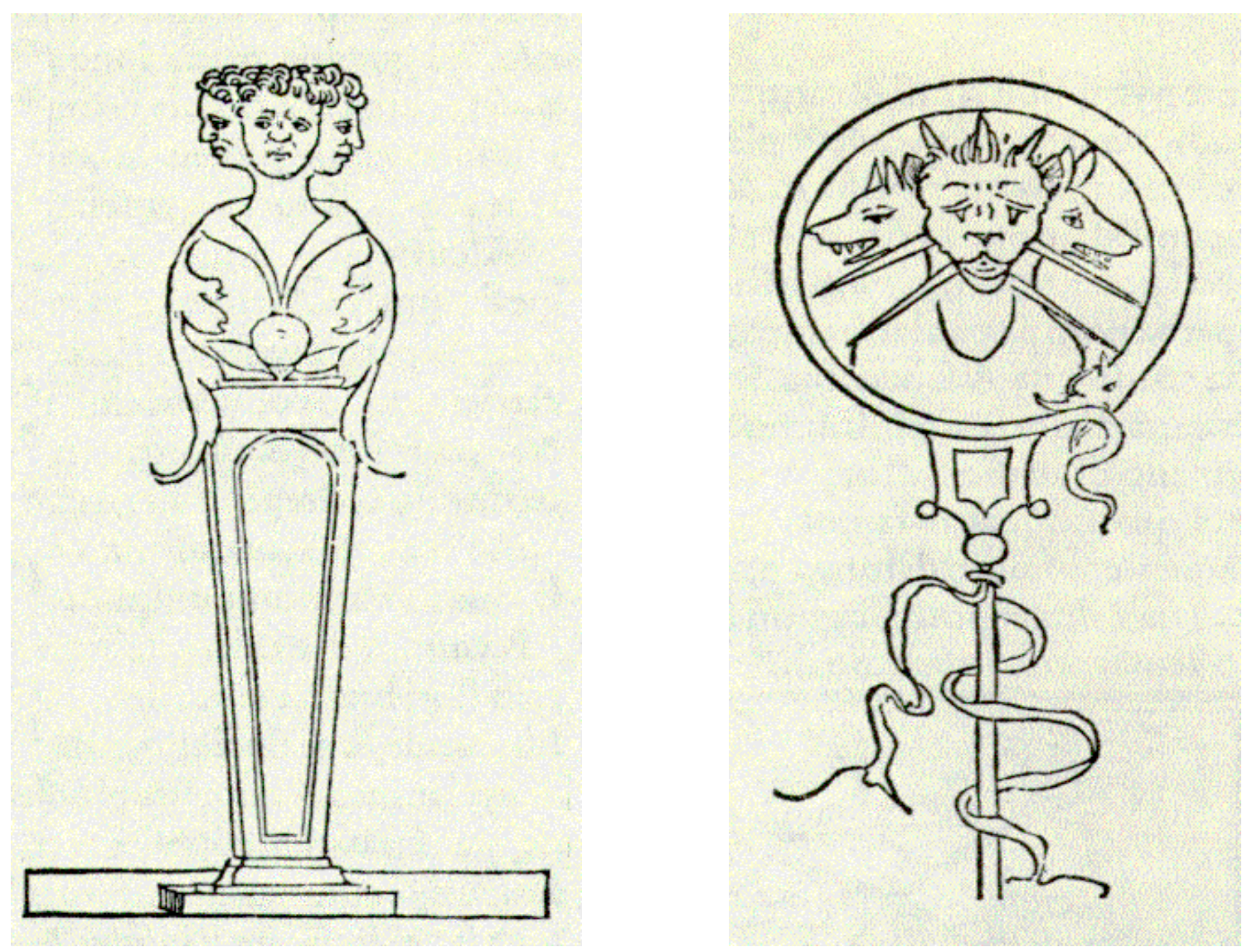

Mário de Sá Carneiro e Fernando Pessoa foi que, modernamente, exploraram bastante tal temática. Em "Floresta do alheamento”, este último diz: “...assim éramos nós obscuramente dois, nenhum de nós sabendo bem se o outro não era ele-próprio, se o incerto outro viveria...” 

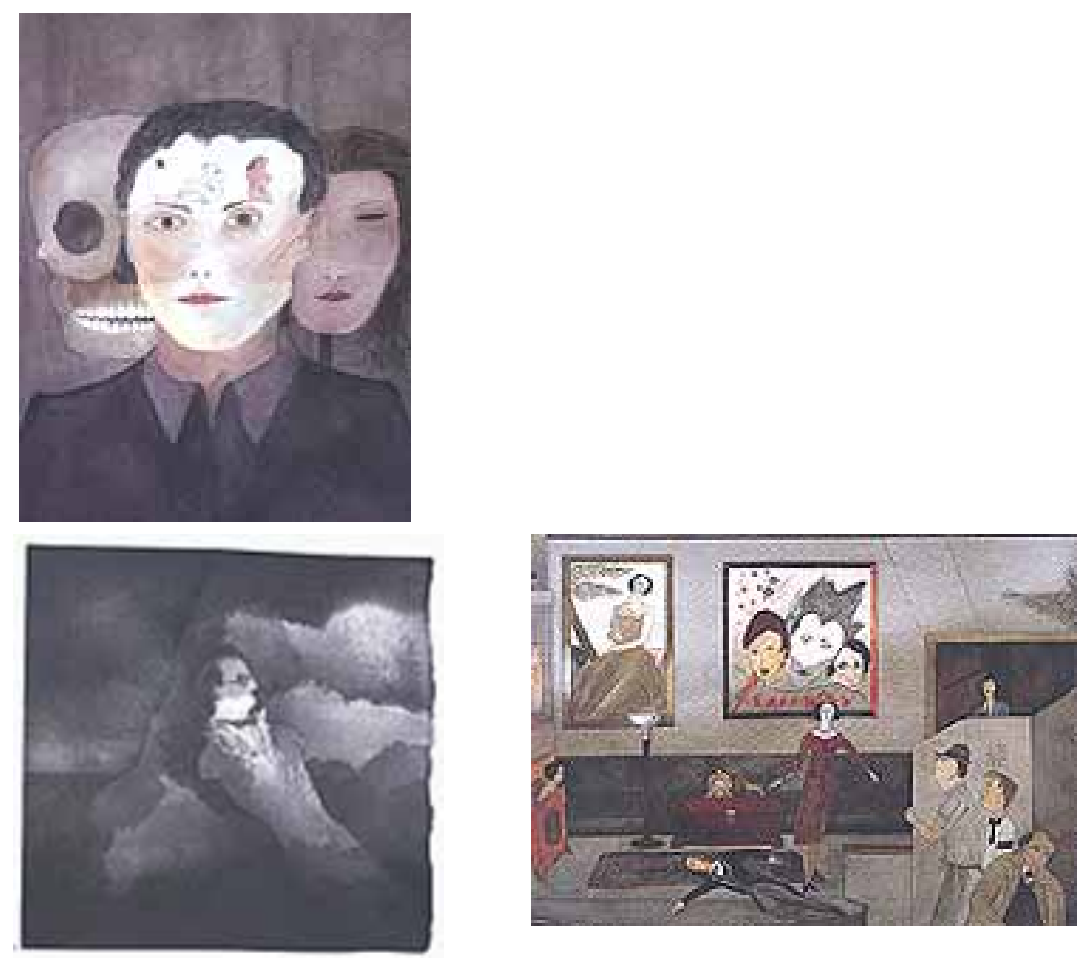

Assim diz Maciel (2002) sobre essa obra do poeta:

O primeiro, Na floresta do alheamento, é um monólogo em prosa, que, em meio a uma atmosfera de irrealidade, encerra uma voz sonâmbula não dizendo nada que não seja ela mesma, visto que o eu que a pronuncia encontra-se num estado paradoxal de "torpor lúcido, pesadamente incorpóreo, estagno, entre um sono e a vigília, num sonho que é uma sombra de sonhar". É um drama por subtração, ou que nem chega a ser, pela extrema volatilidade com que se configura aos olhos e aos ouvidos do leitor.

Esse clima de sonho é reforçado na obra em análise por ser sonho dentro do sonho. Esta tese de que tanto Polifilo quanto Polia são desdobramentos de uma mesma personagem pode ser perseguida tanto pela decomposição do movimento, explorada na imagem a seguir, em que se vê duplos flagrados em duvidosa possibilidade, quanto no fato da história possuir, em sonho, uma narração intercalada, em que ora Polia conta a sua vida ora Polifilo declara-lhe seu amor, restando, na indagação de "se o incerto outro viveria", a pergunta: quem sobrevive? 


\section{DOSSIÊ}

\section{Área Temática: Educação Visual, Linguagens Visuais e Arte}
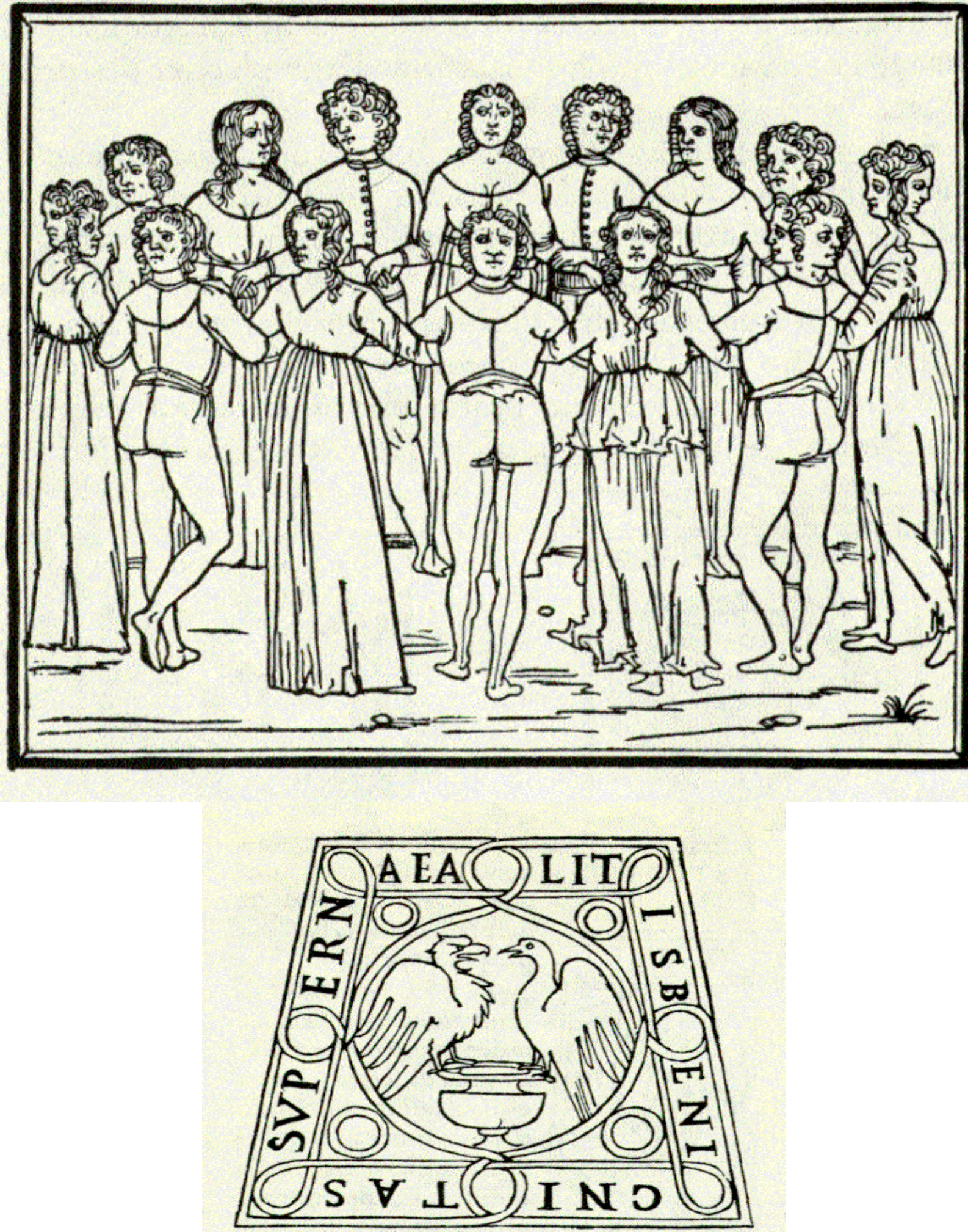

Ou seja, é um erotismo carregado da noção de morte, sublimação da vida diante da consciência inquestionável da finitude humana. De acordo com Battaille, o erotismo da experiência interior necessita da consciência do vivido, caso contrário, estaria negando a própria experiência do corpo. 

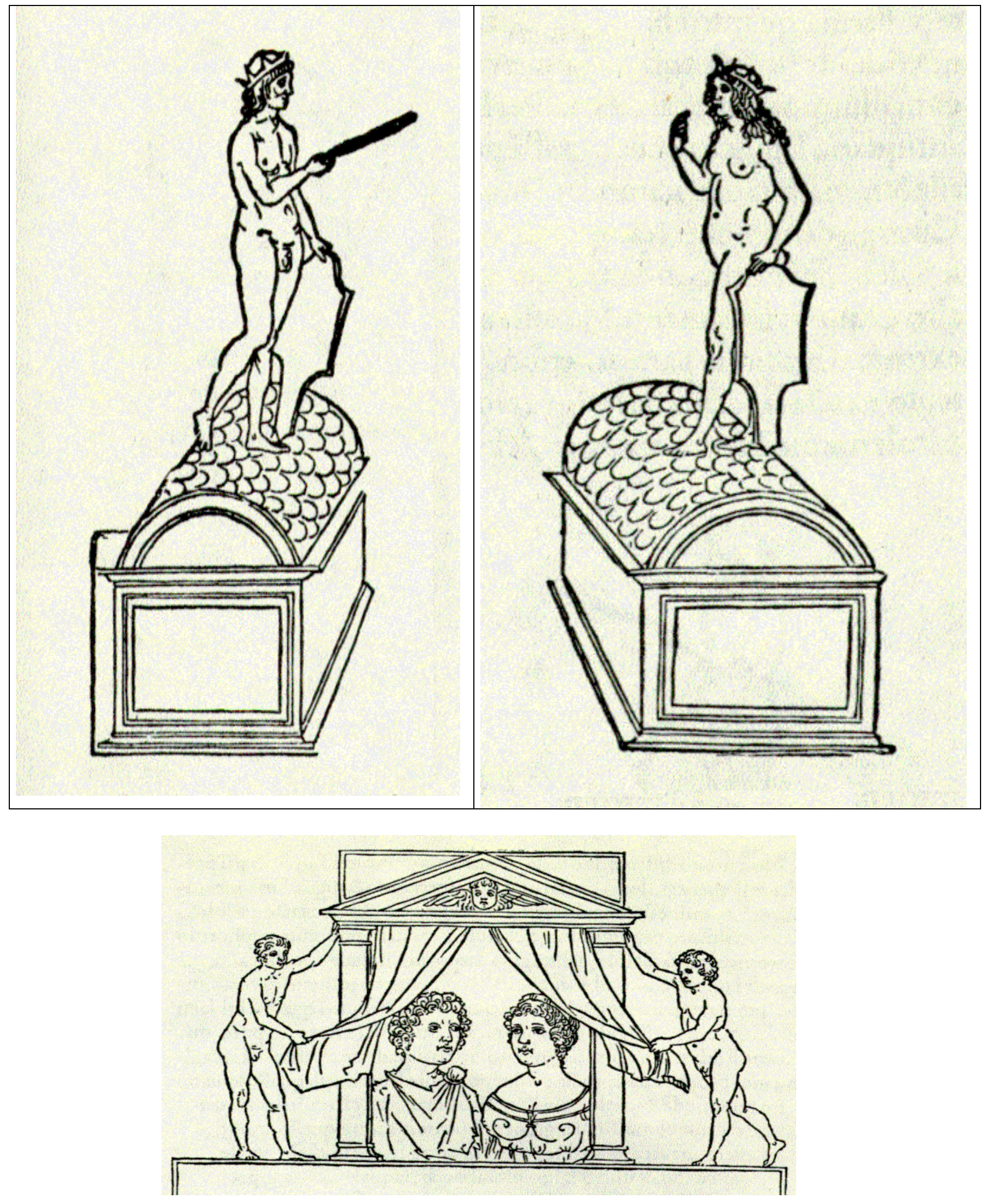

Polifilo é quem morre, mas depois é ressuscitado pelo amor e pelas orações de Polia. Quando ele acorda, lamenta ter findo o sonho, em que pôde se encontrar com Polia, o que não seria mais 
possível na plano real, já que é esta quem está de fato morta. E Polifilo só a pode encontrar porque em sonho.

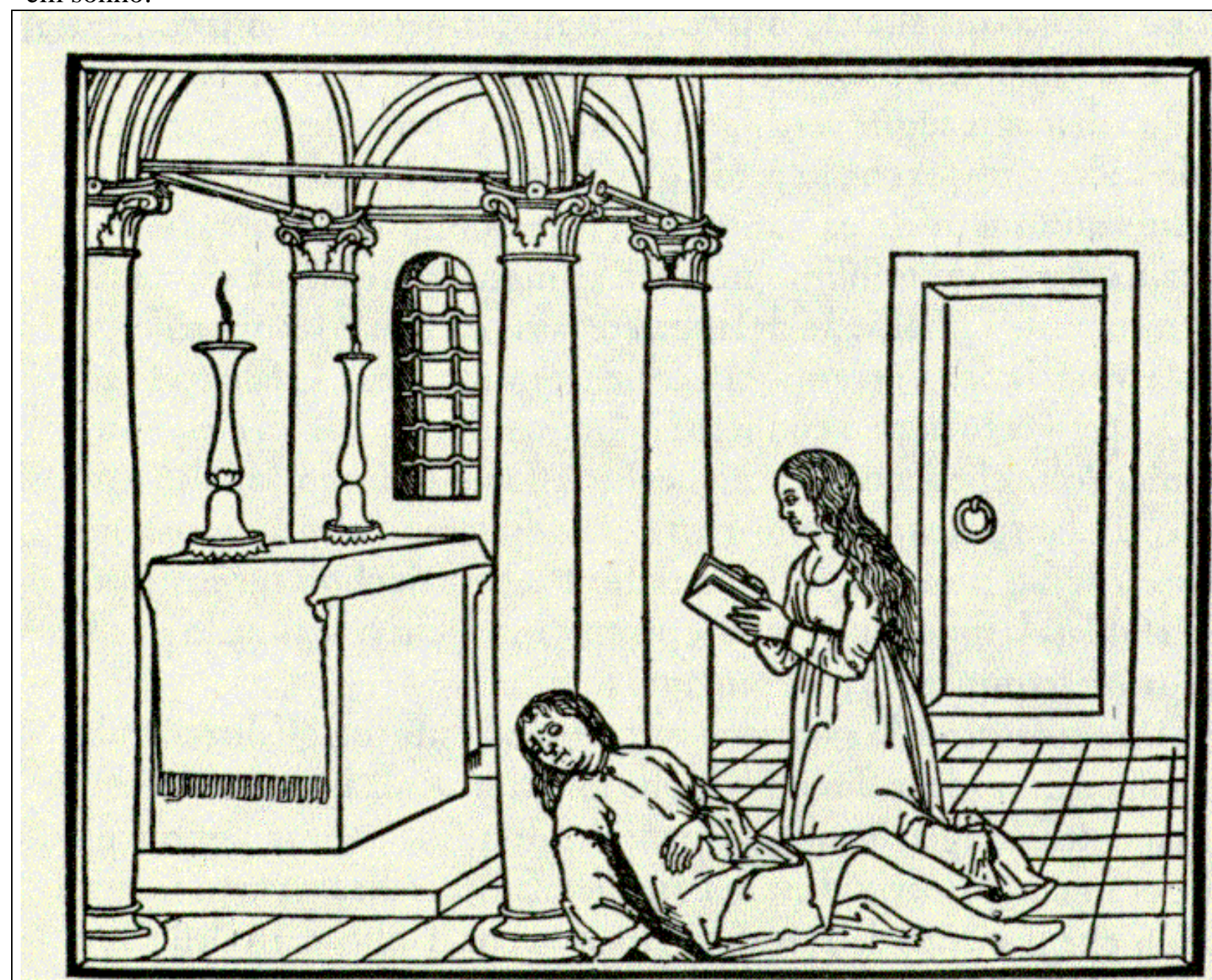

Eros e Psique, também de Fernando Pessoa, formula mais uma vez esse desdobramento da persona:

Conta a lenda que dormia

Uma princesa encantada

A quem só despertaria

Um infante, que vivia

De além do muro da estrada

Ele tinha que tentado,

Vencer o mal e o bem,

Antes que, já libertado,

Deixasse o caminho errado

Por o que à Princesa vem. 
A Princesa Adormecida

Se espera, dormindo espera.

Sonha em morte sua vida, E orna-lhe a fonte esquecida, Verde, uma grinalda de hera.

Longe o infante, esforçado

Sem saber que intuito tem,

Rompe o caminho fadado.

Ele dele é ignorado.

Ela para ele é ninguém.

Mas cada um cumpre o destino

Ela dormindo encantada,

Ele buscando-a sem tino

Pelo processo divino

Que faz existir a estrada.

$E$, se bem que seja obscuro

Tudo pela estrada fora,

E falso, ele vem seguro,

E, vencendo estrada e muro

Chega onde em sono ela mora.

E inda tonto do que houvera,

À cabeça em maresia,

Ergue a mão, e encontra hera,

E vê que ele mesmo era

A Princesa que dormia.

E, para fechar este pequeno artigo, constato que há, então, nessas figurações, predomínio do imaginário sobre o real, assim como predomínio da arte sobre a existência. É a busca do outro sonhado, como uma forma de encontrar a sua própria unidade solar numa humanidade retalhada dos tempos modernos e cujo amor, de acordo com Octavio Paz, é apenas uma chama trêmula, fugidia, interdita, repreendida não pela indecência, mas pela anacrônica limpidez.

\section{REFERÊNCIAS}

BASTOS, R. A. Arquitetura, amor e erostismo. Disponível em: $<\mathrm{C}$ : $\mid$ Documents and Settings\Administrador\Meus documentos\escola 2007\unicamp\ARQUITETURA, AMOR E EROTISMO[1].htm>. Acesso em 14 set. 2007.

BATAILLE, G. O erotismo. Porto Alegre: L\&PM, 1987.

BORGES, J. L. Obras completas. vol. 2. São Paulo: Globo, 1999. 
MACIEL, M. E. Cena viva: Poesia e teatro em Fernando Pessoa, Revista da Cultura, Fortaleza, São Paulo, n. 26, jul. 2002. Disponível em: http://www.revista.agulha.nom.br/ag26pessoa.htm. Acesso em: 5 out. 2007. 